\section{Crinical Memorandum.}

\section{CYSTUCELE OBSTRUCTING LABOR; DELIVERY BY VERSION.}

BY J. N. HALL, M.D. (hARV.), STERLiNG, colorado.

THE interest in this case lies chiefly in the fact that the woman was allowed to become exhausted before help was called for, and hence the child was delivered artificially.

Mrs. I., thirty-eight years of age, eleventh pregnancy, labor pains since waters broke, about fortyeight hours ago. Ten hours before seen she called a midwife. The latter, finding something which prevented progress, summoned aid. When seen by me, 10 A. м., October $23 \mathrm{~d}$, pains were severe, but accomplishing nothing; head presenting, O. R. A. ; marked caput succedaneum; bladder prolapsed in front of the head; pelvis the largest I had ever seen.

An elastic catheter was passed with difficulty, and three ounces of urine removed. From the swollen condition of the parts and the exhaustion, it was thought that delivery would not occur without assistance. Under ether, the head was held well down from the abdomen, but was still so movable that the forceps were abandoned, chiefly from fear of bruising the swollen soft parts. Hence the child was delivered by version with great ease. Weight, about nine pounds. The caput succedaneum extended from one parietal eminence to the other, and was two inches antero-posteriorly.

The convalescence was uninterrupted.

\section{Ifepartæ of Soctetieg.}

\section{MASSACHUSE'TTS MEDICAL SOCIETY. SUFFOLK DISTRIC'T. SECTION FOR OBSTETRICS.}

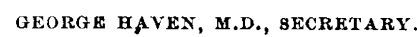

Regular meeting, Wednesday, December 28, 1887, at 19 Boylston Place.

Meeting called to order by the Secretary, at at 8 o'clock. Dr. JohN W. Farlow was elected Cairman for the following year.

The first business in order was a discussion on

THE TREATMENT OF OCCIPITO-POSTERIOR POSITIONS.

The discussion was opened by Dr. C. M. Green, who said: In speaking of the treatment of posterior positions, I shall allude to the etiology only in so far as may be necessary to explain the treatment that seems to me best in the different phases of the condition ; and I shall consider the subject in two divisions, the first embracing those cases where the head is at or above the superior strait, and the second, those where the head has already entered the cavity of the pelvis, as the treatment would differ decidedly under those two conditions.

First, in regard to those cases where the head is at the superior strait or above it. I would say by way of preface that throughout what I shall say I shall regard the pelvis as a normal one. Regarding the fotal head I shall speak as I go along, as the cases would differ somewhat with the size of the head. With the head at the superior strait, and in a posterior position, difficulty is very apt to arise from the head not perfectly engaging. And that is a very interesting point, as to why it does not engage properly. With the head lying in a posterior position the biparietal diameter has gol to pass through the chord which subtends what might be called the sacro-iliac urch on that side of the pelvis towards which the occiput is directed ; that is to say, a line running from the promontory of the sacrum to the middle of the ilio pectineal line on that side. This chord does not equal in its measurement that of either of the oblique diameters. It will be remembered that where the head is attempting to pass the pelvis in an anterior position, the biparietal diameter is going to pass through one of the oblique diameters. For instance, in the O. L. A. position, the biparietal diameter is going to pass through the left oblique diameter of the pelvis and in the $O$. R. A. position the biparietal diameteris to pass through the right oblique diameter, and that it can do readily under normal circumstances. But when the head is attempting to pass in a posterior position, this same biparietal diameter has got to pass through the chord which subtends the sacro-iliac arch on one side, and that does not measure so much. In the great majority of cases the head is not so large but that this diameter of the head can pass through the arch. Still, in a great many cases where the child is well developed, this diameter is just enough too large to prevent its passing easily.

Well, then, the moment there is any resistance whatever to the easy passage of this diameter, the most natural thing to occur is that the head should become slightly extended, or rather, we might perhaps put it in this way, that good flexion does not take place, since a greater resistance is brought to bear on the occipital arm of the cephalic lever. Then when we are called to the case, the head being, as I have said, above the superior strait, we find the occipitofrontal diameter occupying the brim instead of the suboccipito-bregmatic. Now, of course it is impossible for that diameter to pass, and the clinical history in this case is that the woman's labor goes on, the pains are good, bad, or indifferent, the os dilates in part, but does not go on to complete dilatation because the head does not press far enough down, the woman becomes exhausted, and the condition found is, as I have said, no progress, because an improper diameter is trying to pass through the strait.

In that condition of affairs the treatment is obvious, and the ready reply would be to overcome the difficulties in the case, to promote the flexion which has not taken place, to correct the slight extension which has taken place, and let everything go on. The difficulty is that probably the head was in a fair degree of flexion originally, and yet it did not pass. If even we succeed in flexing the head, the woman may have become by that time so tired out that no longer are the pains sufficient to force the head into the pelvis; so that in reference to the advisability of flexing the head and seeing what will happen when that is done, although I do not say that it is of no use whatever to do it, still I have never seen it do much good, owing to the fact that before that is done usually the labor has been so long in progress that the force of the uterine contractions is no longer powerful enough to do the work it would have done if the head had entered properly in the beginning.

The picture is not one which I will attempt to draw 